\title{
THE ANNUAL MEETING IN BETHLEHEM
}

The thirty-sixth Annual Meeting of the American Mathematical Society was held at Bethlehem, Pa., from Thursday to Saturday, December 26-28, 1929. The meeting opened on Thursday afternoon with sessions of the Council and the Board of Trustees, held at the Hotel Bethlehem. The scientific sessions were held at Lehigh University, in the new Packard Laboratory. Friday was devoted to sectional sessions of the Society, and Saturday to a Symposium on the Differential Equations of Engineering. At the dinner on Friday evening at the Hotel Bethlehem Professor J. L. Coolidge was toastmaster, and Professor Oswald Veblen the principal speaker; after the dinner an enjoyable musical program was provided, and also an amusing mathematical skit, written by Professor Tomlinson Fort and acted by members of the mathematical group at Lehigh University. Other pleasant features of this meeting were an excursion to the Bethlehem Steel Works on Thursday, a tea served by the ladies of the faculty on Friday, and an inspection of the old Moravian historical buildings on Saturday, under the guidance of Dean Rau of the Moravian College. At the closing session a unanimous vote was passed thanking President Richards and the Board of Trustees of Lehigh University, the members of the department of mathematics and their wives, and others who assisted in making the meeting an outstanding success.

The attendance included the following one hundred forty-nine members of the Society, as well as a number of engineers, present by invitation:

C. R. Adams, A. A. Albert, Alger, E. S. Allen, Anderton, R. G. Archibald, H. E. Arnold, Bamforth, Barnes, Bauer, A. A. Bennett, W. M. Bond, J. W. Bower, A. B. Brown, H. S. Brown, B. H. Camp, A. D. Campbell, G. A. Campbell, Carver, Alonzo Church, Clawson, Abraham Cohen, L. W. Cohen, Coolidge, C. H. Currier, Curry, Darkow, J. E. Davis, Decker, DeCleene, Dederick, Dostal, Dresden, Farrell, Fite, Fleisher, Flexner, Fort, Philip Franklin, Frink, Fry, C. A. Garabedian, Gehman, D. C. Gillespie, Gilman, M. C. Graustein, W. C. Graustein, Hammatt, Hebbert, E. R. Hedrick, H. B. Hedrick, Hille, Hotelling, Huntington, Hurwitz, Illick, Jeffery, F. E. Johnston, Jonah, Karapetoff, Keeler, Keller, Kichline, Kline, Knebelman, Koehler, Kuhn, Lambert, Lamson, Latimer, D. H. Lehmer, Lehr, D. C. Lewis, Jr., 
Libman, Littauer, N. H. McCoy, McDonnell, MacColl, MacDougall, March, E. N. Martin, Meder, Mellish, H. H. Mitchell, Molina, L. T. Moore, Richard Morris, Marston Morse, Mossman, Mullins, Murnaghan, Neelley, Oakley, Ogburn, E. G. Olds, Ore, F. W. Owens, H. B. Owens, Paradiso, Park, Pierpont, Poritsky, Ransom, Rashevsky; Rau, C. J. Rees, J. B. Reynolds, R. G. D. Richardson, Richeson, J. H. Roberts, Root, J. E. Rowe, Rupp, J. B. Scarborough, Schelkunoff, H. M. Schlauch, Schoonmaker, Seely, Sharpe, I. M. Sheffer, C. A. Shook, Simons, Smail, W. M. Smith, Virgil Snyder, Stanley, Steinmetz, Stocker, Struik, Swartzel, Tamarkin, J. H. Taylor, W. R. Thompson, Thurston, Trjitzinsky, Veatch, Veblen, J. H. Weaver, Weida, E. H. Wells, Whited, Widder, Widmark, Wiener, F. H. M. Williams, John Williamson, A. H. Wilson, Zariski, Zippin.

At the meeting of the Council, the following were elected to sustaining membership in the Society:

Members of the Departments of Mathematics of The George Washington University and of Lehigh University;

Members of the Department of Mathematics of Hunter College.

The following eighty-seven persons were elected to membership in the Society:

Miss Ida Maud Arnett, Central College;

Mr. Norman Hansen Ball, Massachusetts Institute of Technology;

Mr. Henry George Barone, Pennsylvania State College;

Dr. William Dowell Baten, University of Michigan;

Mr. Paul Sherman Bauer, Harvard University;

Professor Harry L. Beard, Oregon State College;

Professor Edward Benjamin Beaty, Oregon State College;

Professor John B. Brandeberry, University of the City of Toledo;

Mr. Hobart C. Carter, University of Missouri;

Mr. L. T. Dunlap, Pennsylvania State College;

Mr. William Elvin Ekman, University of South Dakota;

Mr. Herman Edwin Ellingson, Luther College;

Professor Edward Fleisher, College of the City of New York;

President Frederick Jay Fox, Fox Engineering Company, New York City;

Mr. Gordon Fuller, South Dakota State College;

Mr. Walter Ora Gordon, Pennsylvania State College;

Mr. Clyde Harvey Graves, Pennsylvania State College;

Mr. Elijah Justin Hills, Compton Junior College;

Mr. Alan Nordby Holden, Bell Telephone Laboratories, New York City;

Professor Cecil Thomas Holmes, Bowdoin College;

Mr. I. Owen Horsfall, Cornell University;

Mr. Wyatt Hawkins Ingram, University of Washington;

Mr. Carl Arthur Keeler, Lehigh University;

Mrs. Sarah Youngman Keyser, New York City;

Mr. William L. Kichline, Lehigh University;

Mr. Wendell Holmes Langdon, Yale University;

Mr. Jack Levine, University of California at Los Angeles; 
Mr. Daniel Clark Lewis, Jr., Lehigh University;

Mr. Chester Francis Luther, Stanford University;

Mr. Herbert Burland MacDougal, South Dakota State College;

Sister Marie Cecilia Mangold, Trinity College, Washington;

Miss Harriet F. Montague, University of Buffalo;

Professor Victor Feodor Murray, Catawba College;

Professor V. Ellsworth Pound, University of Buffalo;

Mr. Earl David Rainville, Boulder, Colo.;

Miss Ruth Beatrice Rasmusen, South Dakota State College;

Professor William David Reeve, Teachers College, Columbia University;

Professor Joseph Benson Reynolds, Lehigh University;

Professor Byron David Roberts, Parson College;

Dr. Edward B. Roessler, University of California;

Mr. Harry Gutelius Romig, Bell Telephone Laboratories, New York City;

Miss Helen M. Schlauch, Hunter College;

Professor William S. Schlauch, New York University;

Professor Carl Nathaniel Shuster, State Teachers College, Trenton, N. J.;

Professor Samuel Silberfarb, University of Akron;

Professor Joseph Spear, Northeastern University;

Mr. Hugh Smiley Stanley, Lehigh University;

Mr. Theron S. Taber, Jr., Kern County Junior College;

Professor Charles Frank Thomas, Case School of Applied Science;

Mr. Harold Henry Thorne, University of Sydney;

Mr. Floyd Edward Ulrich, Union College;

Professor Ralph Wilson Veatch, Ursinus College;

Mr. Elvin Leonidas Vernon, University of Wisconsin;

Mr. Robert Merrill Walter, New Jersey College for Women;

Mr. Alexander Weiss, New York City;

Mr. Fred Willard Winters, Bell Telephone Laboratories, New York City;

Professor Harold E. Wolfe, Indiana University;

As nominees of Allyn and Bacon:

Mr. Paul Gerhard Hoel, of University of Minnesota, and Mr. Jacob Yerushalmy, of Johns Hopkins University;

\section{As nominees of Members of the Department of Mathematics of Brown University:}

Mr. Harry LeVern Krall, Mr. Arthur Preston Mellish, Mr. Andrew Fleming Moursund, Professor William Vann Parker (on leave from the University of North Carolina), Mr. Charles Hill Wallace Sedgewick, all of Brown University;

As nominees of Members of the Departments of Mathematics of The George Washington University and of

Lehigh University:

Mr. Paul Bradt and Mr. Jacob Arthur Duerksen, of Washington; Mr. Leland S. Barnes, Mr. Joseph Edward Illick, and Mr. Ralph Newcomb Van Arnam, of Lehigh University; 


\section{As nominees of Members of the Department of Mathematics} of Hunter College:

Miss Bertha Boschwitz, Miss Barbara H. Goldberg, Miss Anna Sacher, Miss Mildred G. Thiesmeyer, Miss Annita Tuller, all of New York City;

As nominees of the National Life Insurance Company of the United States of America:

Miss Florence Lillian Axen, Extension Division, University of Wisconsin, Milwaukee; Dr. Oliver Kenneth Bower, University of Illinois; Miss Marjorie Louise Heckel, Brown University; Mr. Charles Watson Vickery, University of Texas; Mr. Kenneth Warren Wegner, University of Wisconsin;

As nominees of Members of the Department of Mathematics of the University of Wisconsin:

Mr. John V. Atanasoff, Miss Alice May Austin, Mr. James Joseph Barron, Mr. Robert Edward Lowney, Mr. John Roberts Mayor, Mr. Paul L. Trump, Mr. Alva Maurice Tuttle, Miss Louise Webb, all of the University of Wisconsin.

The ordinary membership in the Society is now 1926, including 196 nominees of sustaining members and 81 life members. There are also 37 sustaining members. The total attendance of members at all meetings during the past year was 890 ; the number of papers read was 395 . The number of members attending at least one meeting was 583. At the annual election 209 votes were cast.

The reports of the Treasurer and of the auditors (Professors H. W. Reddick and G. W. Mullins) showed a balance of $\$ 5349.42$, exclusive of the balances in the Bulletin, Transactions, Colloquium, Journal and special funds, and of the life membership reserve. The Society's Endowment Fund, of par value $\$ 76,000$, yielded for 1929 a net income of $\$ 3462.59$; sustaining memberships for the year amounted to $\$ 4300.50$. The amount received from sales of the Society's publications was $\$ 6548.55$. During the year special contributions from members to the amount of $\$ 1284.75$ were received, which prevented a deficit on this year's business. The trustees adopted a budget for 1930 showing estimated expenditures and receipts as $\$ 38,808.38$; and $\$ 37,368.38$, respectively.

The Librarian reported that the Library of the Society now contains 7952 volumes.

The following appointments were reported: to represent the Society at the American Mining Congress held in Washington, December 4-7, 1929, Professor C. E. VanOrstrand; as Com- 
mittee to Nominate Officers, Trustees, and Members of the Council for 1931, Professors H. H. Mitchell (chairman), R. D. Carmichael, O. D. Kellogg, D. N. Lehmer, and R. L. Moore; as Committee on the 1930 Western Autumn Meeting in Columbia, Missouri, Professors Louis Ingold (chairman), W. C. Brenke, M. H. Ingraham, and W. D. A. Westfall; to represent the Society on the Editorial Board of the Annals of Mathematics for three years beginning with 1930, Professors Harry Batemen, G. D. Birkhoff, and J. F. Ritt; to represent mathematics on the committee appointed by the National Research Council to advise regarding the World's Fair in Chicago in 1933, Professor G. A. Bliss.

At the meeting of the Council, Professor R. G. D. Richardson was named to succeed Professor G. C. Evans as one of the three representatives of the Society in the National Research Council.

The report of the Committee on the Reorganization of Prizes was adopted. Details concerning the new plan are given in a separate article in the January issue of this Bulletin.

Editor-in-chief Hedrick reported that Professors H. T. Davis and J. R. Kline had been appointed to the staff of the Bulletin to replace Professors Tullio Levi-Civita and J. H. M. Wedderburn, who have resigned.

It was announced that Professor Marston Morse had accepted the invitation to give the Minneapolis Colloquium and that his subject is Calculus of variations in the large.

It was voted to hold only one meeting of the Society during each of the Convocation weeks of 1930-31 and 1931-32, these meetings to he held at Western Reserve University and the Case School of Applied Science in Cleveland and at Tulane University in New Orleans respectively.

The question of raising the dues, which had been before the Council and Board of Trustees for two years, was finally decided, and the Secretary was instructed to prepare an amendment to the by-laws which will raise the dues to $\$ 8.00$ after three years of membership in the Society.

It was reported that plans were being made to reprint the Veblen Colloquium, and that it was expected that two or three new volumes will be issued during 1930 .

At the annual election, which closed on Friday afternoon, 
the following officers and other members of the Council were chosen:

Vice-Presidents, Professors W. C. Graustein and E. P. Lane. Secretary, Professor R. G. D. Richardson.

Treasurer, Professor G. W. Mullins.

Associate Secretaries, Professors M. H. Ingraham and T. M. Putnam.

Librarian, Professor R. C. Archibald.

Member of the Editorial Committee of the Bulletin, Professor D. R. Curtiss.

Member of the Editorial Committee of the Transactions, Professor F. R. Sharpe.

Member of the Editorial Committee of the Colloquium Publications, Professor Oswald Veblen.

Members of the Council, Professor L. P. Eisenhart, Dr. T. C. Fry, Professors C. H. Sisam, H. E. Slaught, J. L. Walsh, to serve three years; Professor C. G. Latimer, to serve two years; Professor Warren Weaver, to serve one year.

The tellers appointed to count the ballots were Dr. A. A. Albert and Professor R. G. Archibald.

The Symposium on the Differential Equations of Engineering was held on Saturday, President Hedrick in the chair at both sessions. Many engineers were present by invitation, and there was much interesting and illuminating discussion. The following papers were presented:

I. The problem of diffusion, by Professor H. W. March. Discussion led by Mr. R. L. Peek, Jr.

II. Mechanical solution of differential equations, by Professor Vannevar Bush.

III. Plasticity and related problems of non-rigid bodies, by Dr. A. Nadai. Discussion led by Professor S. Timoshenko. IV. Analytical determination of magnetic fields, by Mr. R. H. Park.

V. Problems in elasticity, by Professor S. Timoshenko. Discussion led by Professor G. W. Patterson, Mr. J. N. Goodier, and Professor H. W. March.

The titles and cross-references to the abstracts* of the papers

* The cross-reference gives the number of the volume, the number of the issue in which the abstract is printed, and the number of the abstract itself. 
read at the regular sessions appear below. On Friday morning, President Hedrick presided over the Section of Analysis, Professor Snyder, relieved by Professor Coolidge, over the Section of Geometry, and Professor Camp, relieved by Professor Ore, over the Section of Applications and Algebra. On Friday afternoon, President Hedrick, relieved by Professor Pierpont, presided over the Section of Analysis, and Professor Coolidge over the Section of Algebra, Foundations, and Analysis Situs. Professor Hotelling's paper was communicated by Professor Ore, and Mr. Groat's by Professor Bennett. The papers whose abstract numbers are followed by the letter $t$ were read by title. Professor Calugaréano was introduced by Professor Kasner, and Mr. Peek by Dr. Fry.

\section{Section of Analysis, Friday Morning.}

1. The Green's matrix and expansion problem for systems of integro-differential equations, by Professor F. C. Jonah. (Abstract No. 36-3-67.)

2. Polynomial solutions of linear differential equations; expansions, by Professor I. M. Sheffer. (Abstract No. 36-3-68.)

3. Differential equations containing absolute values of derivatives, by Dr. C. O. Oakley. (Abstract No. 36-3-69.)

4. On irregular kernels, by Professors Einar Hille and J. D. Tamarkin. (Abstract No. 36-3-70.)

5. On the expansion of harmonic functions in terms of harmonic polynomials, by Mr. O. J. Farrell. (Abstract No. 36-3-71.)

6. The oscillation of a sequence, by Professor W. A. Hurwitz. (Abstract No. 36-3-72.)

7. On sequences of continuous functions having a continuous limit, by Professors D. C. Gillespie and W. A. Hurwitz. (Abstract No. 36-3-73.)

8. The integrability of a sequence of functions, by Professor R. L. Jeffery. (Abstract No. 36-3-74.)

9. Some series expansions in the lattice theory of crystals, by Dr. T. H. Gronwall. (Abstract No. 36-3-75-t.)

\section{Section of Geometry, Friday Morning.}

10. Rectangular axes associated with a curve in four-dimensional space, by Professor A. D. Campbell. (Abstract No. 36-3-76.) 
11. Equivalence in hyperspace, by Professor T. R. Hollcroft. (Abstract No. 36-3-77-t.)

12. Linear spaces associated with hyperquadrics, by Professor C. A. Rupp. (Abstract No. 36-3-78.)

13. Plane involutions of order three or four, by Professor F. R. Sharpe. (Abstract No. 36-3-79.)

14. The mapping of monoidal involutions, by Professor F. R. Sharpe. (Abstract No. 36-3-80-t.)

15. On an involutorial transformation found by Montesano, by Professor Virgil Snyder. (Abstract No. 36-3-81.)

16. Notes on the rational plane oscnodal quartic curve, by Professor J. H. Neelley. (Abstract No. 36-3-82.)

17. On the moduli of algebraic functions possessing a given monodromy group, by Dr. Oscar Zariski. (Abstract No. 36-383.)

18. An application of vector analysis to the theory of curves of constant width, by Mr. A. P. Mellish. (Abstract No. 36-3$84-t$.)

19. Invariant treatment of ovals, by Professor D. J. Struik. (Abstract No. 36-3-85.)

20. Content-preserving transformations, by Professor M. S. Knebelman. (Abstract No. 36-3-86.)

21. Solution of the problem of Plateau for any rectifiable contour in n-dimensional euclidean space, by Dr. Jesse Douglas, (National Research Fellow.) (Abstract No. 36-3-87-t.)

22. Solution of the problem of Plateau when the contour is an arbitrary Jordan curve in n-dimensional euclidean space; I, by Dr. Jesse Douglas, (National Research Fellow.) (Abstract No. 36-3-88-t.)

23. Solution of the problem of Plateau when the contour is an arbitrary Jordan curve in n-dimensional euclidean space; II, by Dr. Jesse Douglas, (National Research Fellow.) (Abstract No. 36-3-89-t.)

24. The problem of Plateau and the theorem of Osgood-Caratheodory on the conformal mapping of Jordan regions, by Dr. Jesse Douglas, (National Research Fellow.) (Abstract No. 36-3-90-t.)

25. Generating involutions of infinite discontinuous Cremona groups of $S_{4}$ which leave $V_{3}$ invariant, by Professor Virgil Snyder and Dr. Marguerite Lehr. (Abstract No. 36-3-91.) 
26. Involutions of order $n$ with an $(n-2)$-fold line and their mapping, by Professor F. R. Sharpe. (Abstract No. 36-3-92-t.)

\section{Section of Applications and Algebra, Friday Morning.}

27. Spaces of statistical parameters, by Professor Harold Hotelling. (Abstract No. 36-3-93.)

28. The valuation of a continuous survivorship annuity with a continuous refund of an arbitrarily assigned part of the purchase price, by Professor F. M. Weida. (Abstract No. 36-3-94.)

29. Inextensible chains on fixed plane curves, by Professor J. B. Reynolds. (Abstract No. 36-3-95.)

30. Certain theorems of periodic orbits applied to synchronous machines, by Professor E. G. Keller. (Abstract No. 36-3-96.)

31. On some applications of number-theoretic functions to electrical engineering problems, by Professor B. F. Dostal. (Abstract No. 36-3-97)

32. On th: solution of certain cases of the general equation of diffusion, by Mr. R. L. Peek, Jr. (Abstract No. 36-3-98.)

33. The Dirac theory and sedenions, by Professor D. J. Struik. (ADstract No. 36-3-99-t.)

34. Dynamical systems with integrals quadratic in the velocities, by Professor Philip Franklin. (Abstract No. 36-3-100-t.)

35. Some investigations on finite fields, by Professor Oystein Ore. (Abstract No. 36-3-101.)

36. Newtonian similarity, by Mr. B. F. Groat. (Abstract No. 36-3-102.)

37. The powers of a given ideal of a field which may divide exactly the discriminant of a relative field of mth degree, by Dr. W. R. Thompson. (Abstract No. 36-3-103.)

38. Certain identities in theta functions, by Professor C. G. Latimer. (Abstract No. 36-3-104.)

\section{Section oi Analysis, Friday Afternoon.}

39. On multiple factorial series, by Professor C. R. Adams. (Abstract No. 36-3-105.)

40. A theory of periodic extremals, by Professor Marston Morse. (Abstract No. 36-3-106.)

41. Surface transformations, by Professor F. R. Bamforth. (Abstract No. 36-3-107.) 
42. Singular points of functions which satisfy the partial differential equation of the linear flow of heat, by Professor D. V. Widder. (Abstract No. 36-3-108.)

43. On indefinitely differentiable and quasi-analytic functions, by Professor W. J. Trjitzinsky. (Abstract No. 36-3-109.)

44. Differentiation and integration of matrices, and functional equations in matrices, by Professor I. M. Sheffer. (Abstract No. 36-3-110.)

45. On certain approximations to analytic functions of several variables, by Dr. Hillel Poritsky. (Abstract No. 36-3-111.)

46. A note on an isoperimetric inequality, by Dr. Hillel Poritsky. (Abstract No. 36-3-112-t.)

47. On differential equations admitting polygenic integrals, by Professor Georges Calugaréano. (Abstract No. 36-3-113-t.)

48. On Tchebycheff polynomials of best approximation, by Dr. J. A. Shohat. (Abstract No. 36-3-114-t.)

49. On certain inequalities for Stieltjes integrals, by Dr. J.A. Shohat. (Abstract No. 36-3-115-t.)

50. Mixed systems of linear equations and inequalities, by Miss Helen M. Schlauch. (Abstract No. 36-3-116.)

51. A special prepared system for two quadratics in $n$ variables, by Dr. John Williamson. (Abstract No. 36-3-117.)

52. A note on the multiple factors of a binary form, by Professor L. T. Moore. (Abstract No. 36-3-118.)

53. New results in the theory of normal division algebras, by Dr. A. A. Albert. (Abstract No. 36-3-119-t.)

54. The non-existence of pure Riemann matrices with normal multiplication algebras of order sixteen, by Dr. A. A. Albert. (Abstract No. 36-3-120-t.)

55. Integral bases of all normal quartic fields, by Dr. A. A. Albert. (Abstract No. 36-3-121-t.)

56. A determination of the integers of all cubic fields, by Dr. A. A. Albert. (Abstract No. 36-3-122.)

57. Note on the summation of homogeneous functions of $n$ variables over all points of a modular $n$-space, by Professor W. L. G. Williams. (Abstract No. 36-3-123-t.)

58. The foundations of combinatory logic, by Professor H. B. Curry. (Abstract No. 36-3-124-t.)

59. The universal quantifier in combinatory logic, by Professor H. B. Curry. (Abstract No. 36-3-125.) 
60. The fourth postulates of Riesz and Hausdorf, by Professor Orrin Frink, Jr. (Abstract No. 36-3-126.)

61. A special type of upper semi-continuous collection, by Professor H. M. Gehman. (Abstract No. 36-3-127.)

62. A characterization of the anchor ring by internal properties, by Dr. J. H. Roberts, (National Research Fellow.) (Abstract No. 36-3-128.)

63. A note on a theorem of Mazurkiewicz and Straszewicz, by Dr. J. H. Roberts, (National Research Fellow.) (Abstract No. 36-3-129-t.)

64. Prime ends and indecomposable continua, by Dr. N. E. Rutt, (National Research Fellow.) (Abstract No. 36-3-130-t.)

65. A property of unbounded continua, with applications, by Professor W. A. Wilson. (Abstract No. 36-3-131-t.)

66. Note on equivalence of certain properties of abstract sets, by Professor R. G. Putnam. (Abstract No. 36-3-132.)

R. G. D. RICHARDSON, Secretary 